\title{
PENINGKATAN KEMAMPUAN PENYUSUNAN PERANGKAT PEMBELAJARAN PADA MATA KULIAH MICROTEACHING MELALUI PEMBELAJARAN BERBASIS LESSON STUDY
}

\author{
Nur Rokhimah Hanik*, dan Sri Harsono \\ Universitas Veteran Bangun Nusantara Sukoharjo, Indonesia \\ *Corresponding Author: nurhanik03@gmail.com
}

\section{Article History}

Received : February $27^{\text {th }}, 2021$

Revised : March $13^{\text {th }}, 2021$

Accepted : March 30 ${ }^{\text {th }}, 2021$

Published : May 05 ${ }^{\text {th }}, 2021$
Abstrak: Keragaman perangkat pembelajaran, baik RPP, LKS, Materi Pembelajaran, Instrumen Evaluasi, serta lembar observasi akibat mahasiswa tidak menguasai tentang perangkat pembelajaran yang baik dan benar, membutuhkan waktu khusus pembimbingan antara dosen dengan mahasiswa dalam persiapan penampilan sebagai guru pada mata kuliah Mikroteaching. Oleh karena itu solusi pembelajaran yang berbasis Lesson Study dipilih untuk mengatasi permasalahan tersebut. Adapun tujuan yang ingin dicapai pada penelitian ini adalah;1. Untuk meningkatkan kemampuan mahasiswa dalam penyusunan perangkat pembelajaran pada mata kuliah Microteaching melalui pembelajaran yang berbasis lesson study 2. Untuk meningkatkan kemampuan mahasiswa dalam pelaksanaan proses pembelajaran pada mata kuliah Microteaching melalui pembelajaran yang berbasis lesson study. Metode penelitian yang digunakan adalah Penelitian eksplorasi. Subyek penelitian yang digunakan adalah mahasiswa semester VI regular program studi pendidikan Biologi FKIP Univet Bantara Sukoharjo angkatan 2016/2017 pengambil mata kuliah Microteaching sebanyak 13 orang. Waktu penelitian mulai bulan April sampai Agustus 2019. Data penelitian berupa kemampuan pembuatan perangkat pembelajaran dan kemampuan pelaksanan pembelajaran diperoleh dengan instrumen penilaian yang berupa lembar observasi. Tehnik analisis dana dengan analisa kwalitatif komparasi dengan membandingkan peningkatan kemampuan sebelum pembelajaran dengan lesson study dengan pembelajaran berbasis lesson study. Dari pembelajaran Microteaching berbasis Lesson Study diperoleh hasil terjadi peningkatan nilai rata-rata untuk kemampuan penyusunan Perangkat Pembelajaran dari 77,84 menjadi 89,77 (15,69\%) dan untuk kemampuan pelaksanaan pembelajaran dari 77,08 menjadi 88,23 $(14,23 \%)$. Kategori nilai untuk Perangkat Pembelajaran sebelum Lesson Study $\mathrm{A}=0, \mathrm{~B}=12$ dan $\mathrm{C}=1$. Sedangkan Perangkat Pembelajaran Lesson Study kategori nilai $\mathrm{A}=11$ orang dan $\mathrm{B}=2$ orang, sedang kemampuan pelaksanaan pembelajaran sebelum Lesson Study kategori nilai $\mathrm{A}=0$, $\mathrm{B}=11$ dan $\mathrm{C}=2$, sedangkan kemampuan pelaksanaan pembelajaran setelah Lesson Study kategori nilai $\mathrm{A}=8$ orang dan kategori $\mathrm{B}=5$ orang. Dengan demikian dapat disimpulkan bahwa pembelajaran Microteaching berbasis Lesson Stady dapat meningkatkan kemampuan mahasiswa dalam penyusunan perangkat pembelajaran dan kemampuan pelaksanaan pembelajaran. Dengan hasil penelitian tersebut, masih diperlukan penelitian lanjutan tentang pembelajaran yang berbasis Lesson Study pada mata kuliah Pengenalan Lapangan Persekolahan 2 ( PLP2) untuk mengurangi tugas dosen dan guru pamong membimbing mahasiswa praktikan dalam pembuatan perangkat pembelajaran.

Kata kunci: Perangkat Pembelajaran, Microteaching, dan Lesson Study. 


\section{PENDAHULUAN}

Calon guru atau mahasiswa pengambil matakuliah mikroteaching) diharapkan dapat merencanakan pembelajarannya dengan baik, mulai dari pemahaman terhadap landasan kurikulum, pengembangan silabus, penyusunan Rencana Pelaksanaan Pembelajaran dan Lembar Kerja Siswa, sampai pada penyusunan istrumen evaluasi pembelajaran. Mencermati apa yang termuat dalam (Undang-undang No.20 tahun 2003), (Permen dikbud Nomor 22 tahun 2016, 2016) dan (Undang-undang No.14 tahun 2005) tentang guru dan dosen pasal 8 , berkaitan dengan tugas guru dalam pembelajaran, maka dapat diambil dua hal penting yaitu bahwa guru sebagai agen pembelajaran juga harus mampu merancang pembelajaran dengan baik.

Hampir 25 tahun peneliti telah berpengalaman mengampu mata kuliah Mikroteaching banyak kendala dan permasalahan terjadi pada mahasiswa peserta Mikroteaching, antara lain:

1. Keragaman perangkat pembelajaran, baik RPP, LKS, Materi Pembelajaran, Instrumen Evaluasi, serta lembar observasi akibat mahasiswa hanya sering mencari format di internet. 2. Tidak semua mahasiswa menguasai tentang perangkat pembelajaran yang baik dan benar. Masih banyak yang mampu menulis perangkat pembelajaran namun belum sesuai dengan materi yang ditampilkan. 3. Permasalahan Kurikulum dan format RPP atau perangkat pembelajaran di lapangan yang sering berubah. 4. Tidak tersedia waktu khusus untuk pembimbingan pembuatan perangkat pembelajaran, padahal masih banyak mahasiswa yang butuh pembimbingan dalam pembuatan perangkat pembelajaran.

Dengan alasan di atas dosen pengampupun harus meluangkan waktu khusus untuk mendampingi atau membimbing mahasiswa yang masih belum menguasai tentang pembuatan perangkat pembelajaran. Diperlukan waktu yang sangat banyak untuk dosen pengampu dalam membimbing mereka membuat perangkat pembelajaran, apalagi jika mahasiswa peserta mata kuliah mikroteaching lebih dari 10 orang.

Upaya atau solusi sangat diperlukan untuk mengatasi permasalahan mahasiswa dalam penyusunan perangkat pembelajaran tersebut di atas, karena calon guru sangat dituntut untuk bisa menyusun perangkat pembelajaran yang baik (Asmara et al., 2016). Pembelajaran berbasis Lesson Study dipilih sebagai solusi untuk memantapkan kemampuan mengajar dan menyiapkan perangkat pembelajarannya, karena dengan melaksanakan pembelajaran yang berbasis Lesson Study, wawasan mahasiswa akan berkembang, termotivasi, dan saling bekerjasama dalam menyiapkan latihan megajar yang meliputi menyiapkan perangkat pembelajaranya. Pembelajaran berbasis Lesson Studi merupakan salah satu kulminasi atau muara program yang memberikan kesempatan kepada para guru dan calon guru untuk memantapkan kompetensi pedagogik, kepribadian, profesional dan sosial dalam rangka memperbaiki atau meningkatkan mutu pembelajarannya agar dapat menjadi calon guru atau guru yang bermutu dan lebih baik. (Murtisal et al., 2017).

Lesson Study merupakan kegiatan yang dapat mendorong terbentuknya sebuah komunitas belajar (learning society) yang secara konsisten dan sistematis melakukan perbaikan diri, baik pada tataran individual maupun manajerial (Slamet Mulyana, 2007). (Sudrajat, 2008) dan (Susanto, 2011). memberikan rumusan tentang Lesson Study sebagai salah satu model pembinaan profesi pendidik melalui pengkajian pembelajaran secara kolaboratif dan berkelanjutan berlandaskan pada prinsippsrinsip kolegalitas dan mutual learning untuk membangun komunitas belajar. Kebersamaan ini terjadi pada pembahasan Rencana Mutu Pembelajaran (RMP) dan perangkatnya, seperti media, LKS atau alat pembelajaran, instrument evaluasi, dan lain-lain serta implementasi RMP di kelas juga kegiatan refleksi yang mendiskusikan kegiatan pembelajaran yang baru saja dilaksanakan berdasarkan hasil observasi dalam rangka perbaikan RMP dan perbaikan pembelajaran selanjutnya (Sukirman, 2011) dan (Hanik; Nur Rokhimah dan Harsono; Sri., 2016).

Dalam kegiatan Lesson Study ini dapat dikembangkan tingkat profesionalisme mahasiswa calon guru karena dilaksanakan secara kolaborasi antara mahasiswa satu dengan yang lainnya berdasarkan prinsip-prinsip kolegalitas (kesejawatan) dan (Sudrajat, 2008) mutual learning (pembelajaran yang saling membantu). Mahasiswa atau peserta yang sudah paham atau memiliki ilmu lebih harus mau 
berbagi dengan mahasiswa lain yang belum paham, dan sebaliknya mahasiswa yang belum paham harus mau bertanya kepada mahasiswa atau peserta yang sudah paham. Dengan pelaksaan pembelajaran yang berbasis Lesson Study pada mata kuliah Mikroteaching tersebut diharapkan dosen pengampu tidak lagi dibebani dengan banyak waktu untuk membimbing satu demi satu mahasiswa dalam penyusunan perangkat pembelajaran. Perangkat pembelajaran dalam Mikroteaching dapat disusun dalam kegiatan Plan dan dibahas secara bersama-sama dalam waktu refleksi dari hasil observasi yang dilakukan.

Berdasar latar belakang tersebut di atas telah dilakukan penelitian dengan judul: "Peningkatan Kemampuan Penyusunan Perangkat Pembelajaran Pada Mata Kuliah Mikroteaching Melalui Pembelajaran Berbasis Lesson Study" dengan tujuan; 1. Untuk meningkatkan kemampuan mahasiswa dalam penyusunan perangkat pembelajaran pada mata kuliah Mikroteaching melalui pembelajaran yang berbasis lesson study. 2. Untuk meningkatkan kemampuan mahasiswa dalam pelaksanaan proses pembelajaran pada mata kuliah Mikroteaching melalui pembelajaran yang berbasis lesson study.

\section{METHODS}

Penelitian dilakukan di Program Studi Pendidikan Biologi Fakultas Keguruan dan Ilmu Pendidikan Universitas Veteran Bangun Nusantara Sukoharjo. Penelitian dilaksanakan pada bulan April sampai dengan bulan Agustus tahun 2019. Subyek penelitian yang digunakan adalah mahasiswa semester VI regular program studi pendidikan Biologi FKIP Univet Bantara Sukoharjo angkatan 2016/2017 pengambil mata kuliah Microteaching sebanyak 13 orang

Target atau hasil yang diharapkan harus dicapai dari kegiatan ini adalah perbaikan atau peningkatan kualitas perangkat pembelajaran dari rata-rata skor 66 menjadi $\geq 80$ dengan indikator :

1. Kelengkapan silabus, 2. Kesesuaian Kompetensi inti dan KD dengan materi yang disiapkan 3. Kelengkapan Indikator capaian pembelajaran 4..Kelengkapan komponen tujuan pembelajaran 5. Kesesuaian materi dengan $\mathrm{KD}$ dan tujuan pembelajaran 6. Kesesuaian Instrumen evaluasi Kognitif dengan tujuan pembelajaran 7. Kesesuaian lembar observasi psikomotor dengan metode atau strategi yang digunakan 8. Kesesuaian Langkah - langkah pembelajaran dengan strategi yang digunakan 9 . Kesesuaian media dengan materi pembelajaran 10. Kesesuaian LKS dengan Metode atau model pembelajaran

Selain Perangkat Pembelajaran (PP) juga ditarjetkan terjadi peningkatan kemampuan pelaksanaan proses pembelajaran dari rata-rata skor 70 menjadi $\geq 83$. Adapun indikator yang diamati adalah : 1 . Penyiapan media yang memadai 2. Kesesuaian media dengan materi dan metode 3. Kesesuaian metode pelaksaan dengan metode dalam RPP 4. Kesesuaian materi yang disampaikan dalam pembelajaran dengan RPP 5. Kesesuaian materi dengan tujuan dalam RPP 6. Kemampuan penyampaian materi sesuai dengan RPP 7. Kemampuan memanfaatkan waktu sesuai dengan RPP 8. Kemampuan pelaksanaan pengelolaan kelas 9. Kesesuaian tujuan LKS dengan tujuan pembelajaran dalam RPP 10. Melaksanakan postes atau tidak

Tehnik pengumpulan data dengan dokumentasi RPP dan perangkat pembelajaran lainnya yang dibuat dan digunakan selama 3 siklus pembelajaran berbasis lesson study serta observasi selama kegiatan plan, do dan see untuk memperoleh data tentang kemampuan pelaksanaan pembelajaran. Sedangkan Analisis Data yang digunakan adalah diskriptif kwalitatif terhadap RPP dan perangkat pembelajaran lainnya selama 3 siklus pembelajaran, serta kemampuan pelaksanaan pembelajarannya (Sugiyono, 2013).

\section{HASIL PENELITIAN DAN PEMBAHASAN}

\section{Hasil Penelitian}

Pada penelitian ini diawali dengan analisis kondisi kemampuan awal mahasiswa sampel.

Kondisi awal pelaksanaan pembelajaran matakuliah Mikroteaching pada mahasiswa semester 6 regular, kemampuan penyusunan perangkat pembelajaran dari 13 mahasiswa masih belum memuaskan dan terdapat 1 mahasiswa yang bernilai 65 (kategori C). Aktivitas kemampuan dalam pelaksanaan pembelajaran juga belum memuaskan dan ada 2 mahasiswa bernilai 65 dan 68 (kategori C). Dosen pengampu mata kuliah sangat tersita waktunya dalam membimbing mahasiswa menyusun perangkat pembelajaran. Padahal 
model perangkat pembelajaran di lapangan/di sekolah sering berubah. Tidak sesuai dengan model/format pada saat mereka menempuh mata kuliah Kurikulum dan Perangkat Pembelajaran Biologi SMA.

Dengan kondisi tersebut di atas kemudian pembelajaran mocroteaching yang konvensional dirubah dengan pembelajaran yang berbasis Lesson Study, namun tidak meninggalkan esensi pelaksanan pembelajaran Microteaching.

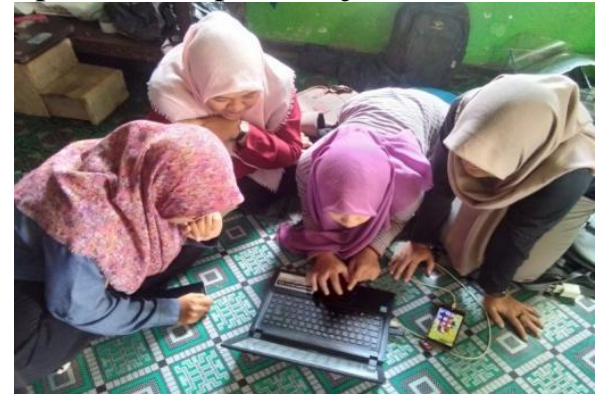

Gambar: kegiatan plan
13 mahasiswa pengambil mata kuliah Microteaching dibagi menjadi 3 kelompok belajar dan tiap kelompok terdiri 4-5 orang.

a. Kelompok 1 terdiri 5 orang, dengan tema/KD tentang pencernaan makanan $b$. Kelompok 2 terdiri 4 orang dengan tema/KD tentang metabolisme c. Kelompok 3 terdiri 4 orang dengan tema/KD tentang Genetika dan Lingkungan.

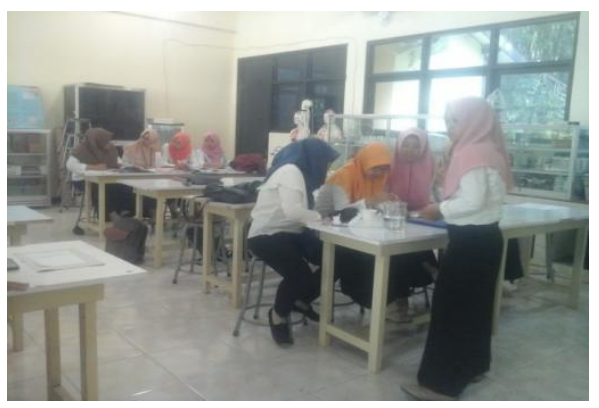

Gambar: kegiatan Doo

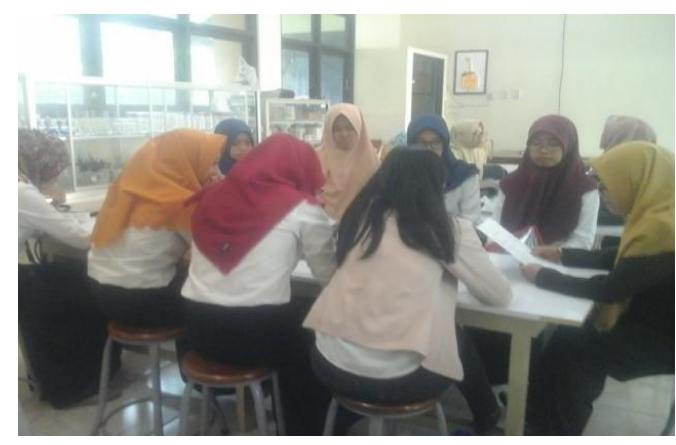

Gambar: kegiatan See

Setiap akan bertugas sebagai guru model anggota kelompok terlebih dahulu harus menyusun perangkat pembelajaran secara bersama-sama dalam kegiatan Plan. Dan pada waktu pelaksanaan pembelajaran microteaching kelompok yang bertugas sebagai guru model secara bergantian maju dan juga bertugas sebagai siswa pada saat tidak sebagai guru model. Sedangkan satu kelompok sebagai observer mengamati pelaksanaan pembelajaran dilanjutkan dengan paparan hasil observasi dari kelompok mahasiswa observer tentang kelebihan dan kekurangan dalam penampilan guru, aktifitas siswa, kelengkapan media, serta perangkat pembelajaran yang dibuat.

Dalam kegiatan refleksi rata-rata mahasiswa merasa gugup pada saat tampil mengajar, dan merasa belum optimal guru model dan mencermati perangkat pembelajarannya. Hasil observasi akan dibahas pada waktu refleksi yaitu pada akhir jam perkuliahan microteahing, karena pembelajaran Lesson study terdiri dari plan, do dan see.

Pada saat kegiatan refleksi guru model secara bergantian dipersilahkan untuk menceritakan tentang pengalaman dan kendala dalam penampilannya, kemudian dalam menyiapkan media pembelajarannya.

Sedangkan perangkat pembelajarannya hampir semua sudah sesuai aturan, hanya pada lampiran materi ada 2 mahasiswa yang belum maksimal dalam pembuatan materinya.

Hasil penerapan pembelajaran yang berbasis Lesson study tersebut ternyata dalam 3 siklus sebanyak 6 kali pertemuan 
terjadi peningkatan dalam kemampuan penyusuanan perangkat pembelajaran dan kemampuan pelaksanaan pembelajaran.
Adapun perubahan nilai tersebut dapat dilihat dalam tabel di bawah.

Tabel 2 : Perbandingan hasil nilai Perangkat Pembelajaran (PP) dan Peerteaching sebelum dan sesudah pembelajaran berbasis Lesson Study

\begin{tabular}{|c|l|c|c|c|c|c|c|}
\hline No & Nama Mhs & $\begin{array}{c}\text { Nilai } \\
\text { PP }\end{array}$ & $\begin{array}{c}\text { Nilai } \\
\text { PP LS }\end{array}$ & $\begin{array}{c}\% \\
\text { Kenaikan }\end{array}$ & $\begin{array}{c}\text { Nilai } \\
\text { Peer }\end{array}$ & $\begin{array}{c}\text { Nilai } \\
\text { Peer LS }\end{array}$ & $\begin{array}{c}\% \\
\text { kenaikan }\end{array}$ \\
\hline 1. & Anggi Larasati & 80 & 87 & 8,75 & 80 & 83 & 3,75 \\
\hline 2. & Winda N.A & 80 & 83 & 3,75 & 80 & 91 & 13,75 \\
\hline 3. & Oktaviani E.A & 82 & 90 & 9,75 & 83 & 98 & 18,07 \\
\hline 4. & Fita Murwanti & 80 & 93 & 16,25 & 80 & 84 & 5,00 \\
\hline 5. & Acna Clara & 75 & 94 & 25,33 & 70 & 98 & 40,00 \\
\hline 6. & $\begin{array}{l}\text { Laprischa } \\
\text { Dewi }\end{array}$ & 82 & 97 & 18,29 & 83 & 91 & 9,63 \\
\hline 7. & Tami Subekti & 82 & 90 & 9,75 & 83 & 87 & 4,82 \\
\hline 8. & Murni Aisah & 80 & 87 & 8,75 & 80 & 84 & 5,00 \\
\hline 9. & Dhesti Nurul & 70 & 90 & 28,57 & 68 & 89 & 21,00 \\
\hline 10. & $\begin{array}{l}\text { Tri Prawesti } \\
\text { W }\end{array}$ & 78 & 93 & 19,23 & 75 & 95 & 26,67 \\
\hline 11. & $\begin{array}{l}\text { Dita Nur } \\
\text { Aspita }\end{array}$ & 78 & 90 & 15,38 & 75 & 94 & 25,33 \\
\hline 12. & Rokhana S & 80 & 90 & 12,50 & 80 & 81 & 1,25 \\
\hline 13. & $\begin{array}{l}\text { Rina } \\
\text { Purnamasari }\end{array}$ & 65 & 83 & 27,69 & 65 & 72 & 10,77 \\
\hline & Jumlah Total & 1012 & 1167 & 203,99 & 1002 & 1147 & 185,04 \\
\hline & \multicolumn{1}{|l|}{ Rata-rata } & 77,84 & 89,77 & 15,69 & 77,08 & 88,23 & 14,23 \\
\hline
\end{tabular}

Tabel 3: Perbandingan kategori nilai Perangkat Pembelajaran dan

Peer mahasiswa sebelum dan setelah pembelajaran berbasis LS

\begin{tabular}{|c|c|c|c|c|c|c|}
\hline No & Nilai & $\begin{array}{c}\text { Kategori } \\
\text { nilai }\end{array}$ & PP & PP LS & Peer & Peer LS \\
\hline 1 & $86-100$ & A & 0 & 11 & 0 & 8 \\
\hline 2 & $70-84$ & B & 12 & 2 & 11 & 5 \\
\hline 3 & $60-70$ & C & 1 & 0 & 2 & 0 \\
\hline
\end{tabular}




\section{Pembahasan}

\section{a. Kemampuan Penyususnan Perangkat Pembelajaran (PP)}

Kemampuan penyusunan perangkat pembelajaran setelah Lesson Studi terjadi peningkatan dari 77,84 menjadi 89,77 (meningkat 15,69\%). Semula 12 mahasiswa memperoleh nilai $\mathrm{B}$ dan 1 mahasiswa memperoleh nilai $\mathrm{C}$, setelah penerapan pembelajaran Lesson Studi 11 mahasiswa memperoleh nilai A dan 2 mahasiswa memperoleh nilai $\mathrm{B}$.

Dalam kegiatan plan mahasiswa dalam 1 kelompok membahas RPP secara bersama-sama dan saling memberikan masukan. Sedangkan pada saat refleksi mahasiswa antar kelompok saling memberikan masukan dan saran untuk perbaikan pelaksanaan pembelajaran. Dengan demikian RPP dan pelaksanaan pembelajaran mereka menjadi lebih baik dibanding sebelum penerapan pembelajaran yang berbasis Lesson Study. Hal tersebut sesuai dengan hasil penelitian (Rahayu et al., 2018) menyatakan bahwa dengan Lesson Study terjadi peningkatan kompetensi dan profesionalisme guru, meningkatankan kualitas proses dan hasil pembelajaran serta pengembangan pembelajaran yang demokratis berbasis paradigma konstruktivsme.

Berdasarkan hasil penelitian dari (Sudirman, 2013) dan (Harsono, 2013) dengan pembelajaran Lesson Study guru dapat: 1. Kemampuan menyiapkan perangkat pembelajaran yang meliputi RPP (di dalamnya ada model dan metode), alat evaluasi, dan media 2. Kemampuan melaksanakan pembelajaran apa yang akan dikerjakan oleh dan siswa (sesuai RPP), 3. Membiasakan kerjasama untuk memperbaiki proses pembelajaran yang berakibat hasil belajar siswa meningkat, karena didalam Lesson Study ada pembelajaran kolaborasi satu sama lainnya saling menyumbangkan ide dalam perbaikan pembelajaran.

Slamet Mulyana (2007) memberikan rumusan tentang Lesson Study sebagai salah satu model pembinaan profesi pendidik melalui pengkajian pembelajaran secara kolaboratif dan berkelanjutan berlandaskan pada prinsip-psrinsip kolegalitas dan mutual learning untuk membangun komunitas belajar.

Plan lesson study ini terkait dengan pembuatan RPP atau mendesign rencana pembelajaran. Sedangkan do berhubungan dengan kesesuaian pelaksanaan pembelajaran dengan RPP yang kemudian dibahas dalam see lesson study. Jika dalam do masih ada ketidak sesuaian maka guru model perlu melakukan perbaikan dan bisa dilaksanakan pada siklus selanjutnya. Jika do sudah sesuai dengan RPP maka tujuan kegiatan lesson study sudah tercapai. Menurut Lewis dalam (Maghfiroh \& Umar, 2011) (Rahayu et al., 2018) manfaat lesson study yaitu meningkatkan mutu pembelajaran di kelas karena guru mengembangkan lesson study berdasarkan "sharing" dan berkolaborasi dengan guru lain, melakukan penelitian dengan mengkaji pembelajaran. Guru melakukan lesson study secara kolaboratif yang nantinya akan terdapat berbagai pendapat yang dapat disharingkan untuk mendapatkan perbaikan pembelajaran.

\section{b. Kemampuan Pelaksanaan Pembelajaran}

Kenaikan hasil sebelum dan setelah pembelajaran dengan LS tersebut (tabel 2 dan 3) terlihat bahwa sebelum Lesson Studi 11 mahasiswa memperoleh nilai B dan 2 mahasiswa memperoleh nilai $\mathrm{C}$, setelah Lesson Studi 8 mahasiswa memperoleh nilai A dan 5 mahasiswa memperoleh nilai B. Pada kegiatan pembelajaran berbasis Lesson Study tersebut terjadi belajar bersama atau berbagi pengalaman, dan saling memberi masukan. Dalam pembelajaran peerteaching yang berbasis Lesson Study ini terjadi prinsip kolegalitas dan mutual learning (saling belajar) diterapkan dalam berkolaborasi ketika melaksanakan kegiatan Lesson study. Dengan kata lain, peserta kegiatan Lesson study tidak boleh merasa superior (merasa paling pintar) atau imperior (merasa rendah diri) tetapi semua peserta kegiatan Lesson study harus diniatkan untuk saling belajar. Peserta yang sudah paham atau memiliki ilmu lebih harus mau berbagi dengan peserta yang lebih paham, sebaliknya peserta yang belum paham harus mau bertanya kepada peserta yang sudah paham. Keberadaan nara sumber dalam forum lesson study harus bertindak sebagai fasilitator, bukan Instruktur. Fasilitator harus dapat memotivasi peserta mengembangkan potensi yang dimiliki para peserta agar para peserta dapat maju bersama. (Siti Zubaidah dalam (Nurhadi et al., 2019).

(Bill Cerbin \& Bryan Kopp. A Brief, n.d.) mengemukakan bahwa Lesson Study memiliki 4 (empat) tujuan utama, yaitu untuk : (1) memperoleh pemahaman yang lebih baik tentang bagaimana siswa belajar dan guru mengajar; (2) memperoleh hasil-hasil tertentu yang dapat dimanfaatkan oleh para guru lainnya, di luar 
pembelajaran secara sistematis melalui inkuiri kolaboratif. (4) membangun sebuah pengetahuan pedagogis, dimana seorang guru dapat menimba pengetahuan dari guru lainnya. Dari hasil penelitian (Ahmadi., 2012) Kegiatan Lesson Study, dapat meningkatkan kemampuan guru SMP Negeri Model Terpadu Bojonegoro dalam menyusun RPP Inovatif. Indikator kinerja: Sekurang-kurangnya $90 \%$ guru menunjukkan kemampuan yang baik dalam menyusun RPP Inovatif (nilai rata-rata 4,00-5,00) dalam skala 15, tercapai pada akhir siklus III dengan pencapaian $91,6 \%$

Selain itu pembelajaran berbasis Lesson study bertujuan untuk melakukan pembinaan profesi pendidik secara berkelanjutan agar terjadi peningkatan profesionalisme pendidik terus menerus. Membangun komunitas belajar adalah budaya membangun budaya yang memfasilitasi anggotanya untuk saling belajar, saling koreksi, saling menghargai, saling bantu, saling menahan ego. Komunitas belajar tidak ada batasan, semakin lama semakin baik. Berkenaan dengan pembelajaran, tidak ada pembelajaran yang sempurna, selalu ada celah untuk terus memperbaikinya, karena itu pembelajaran harus dikaji secara terus menerus agar lebih baik dan lebih baik. Pengkajian pembelajaran dimakudkan untuk mencari solusi terhadap permasalahan pembelajaran agar terjadi peningkatan mutu pembelajaran terus menerus. Obyek kajian pembelajaran dapat meliputi antara lain, materi ajar, metode/strategi/pendekatan pembelajaran, LKS (Lembar Kerja Siswa), media pembelajaran, setting kelas, assesmen, atau hal-hal yang terkait dengan pemberdayaan siswa. Mengapa pengkajian pembelajaran dilakukan secara berkolaborasi? Karena lebih banyak masukan perbaikan akan meningkatkan mutu pembelajaran itu sendiri. Mungkin menurut diri sendiri rasanya persiapan pembelajaran sudah bagus, namun apabila mendapat masukan dari orang lain mungkin akan lebih meningkatkan mutu persiapa pembelajaran yang akhirnya akan meningkatkan kwalitas dalam proses pembelajaran.

\section{KESIMPULAN}

Dari hasil penelitian dapat disimpulakan bahwa pembelajaran mikroteaching yang berbasis Lesson Study dapat meningkatkan kemampuan mahasiswa dalam penyusunan perangkat pembelajaran serta meningkatkan kemampuan dalam pelaksanaan pembelajaran. Dengan demikian jika diaplikasikan dalam perkuliahan microteaching selanjutnya dapat mengurangi beban dosen dalam bimbingan perangkat pembelajaran. Masih perlu dikembangkan penelitian lanjutan pada mata kuliah PLP2 (Pengenalan Lapangan Persekolahan 2) untuk meringankan tugas guru pamong dan dosen pembimbing PLP2.

\section{UCAPAN TERIMA KASIH}

Ucapan terima kasih saya sampaikan kepada dekan Fakultas Keguruan dan Ilmu Pendidikan serta ketua LPPM Universitas Veteran Bangun Nusantara Sukoharjo yang telah memberikan ijin dalam penelitian ini, serta para mahasiswa pendidikan Biologi angkatan tahun 2016 yang telah terlibat dan membantu pelaksanaan penelitian dari awal sampai akhir. Penelitian ini dilaksanakan dengan dana APBU Universitas Veteran Bangun Nusantara Sukoharjo tahun anggaran 2019 sebesar 6 juta serta dana mandiri sebesar 4 juta.

\section{REFERENSI}

Ahmadi (2012). Meningkatkan Kemampuan Guru Dalam Menyusun Perangkat Pembelajaran Inovatif Melalui Lesson Study. Proceeding Biology Education Conference, 257-262. https://jurnal.uns.ac.id/prosbi/article/view/ $7460 / 6628$

Asmara, J., Massawet, E., \& Rambitan, V. (2016). Analisis Permasalahan Guru Terkait Pengembangan Perangkat Pembelajaran Berbasis Model Think Talk Write (Ttw) Dan Permasalahan Siswa Terkait Keterampilan Bertanya Siswa Dalam Pembelajaran Ipa Biologi. Jurnal Pendidikan - Teori, Penelitian, dan Pengembangan, 1(10), 2059-2065.

Bill Cerbin \& Bryan Kopp. A Brief. (n.d.). Introduction to College Lesson Study. Lesson Study Project.http ://www.uwlax.edu/sotl/lsp/ind ex2.htm.

Hanik; Nur Rokhimah dan Harsono; Sri. (2016). Peningkatan Aktivitas dan Hasil Belajar Mahasiswa pada Mata Kuliah Anatomi Tumbuhan Melalui Model Pembelajaran Komparasi yang Berbasis Lesson Study. JPMIPA.. 7 (2) Juli 2016. ISSN: 20860234. Hal. 25-31. 
Harsono, S. \& N. R. H. (2013). Upaya Peningkatan Kemampuan Penyusunan Perangkat Pembelajaran melalui Pembelajaran Lesson Study pada Mata Kuliah Morfologi Tumbuhan.

Maghfiroh, T., \& Umar, H. M. (2011). Pelaksanaan Lesson Study Berbasis Sekolah Dalam Meningkatkan Profesional Guru Pada Mata Pelajaran IPS (Ilmu Pengetahuan Sosial) Di SMP Negeri 1 Jember. Jurnal UNEJ Jurnal Pendidikan Ekonomi, $9, \quad 35-47$. https://jurnal.unej.ac.id/index.php/JPE/arti cle/view/3413/2679

Murtisal, E., Nurmaliah, C., \& Safrida, S. (2017). Implementasi Pembelajaran Berbasis Lesson Study Terhadap Kompetensi Pedagogik dan Keterampilan Proses Sains Guru Biologi SMA Negeri 11 dan MA Negeri 3 Kota Banda Aceh. BIOTIK: Jurnal Ilmiah Biologi Teknologi dan Kependidikan, $4(1), \quad 81$. https://doi.org/10.22373/biotik.v4i1.1074

Nurhadi, A., Atiqullah, A., \& Mubah, H. Q. (2019). Penguatan Pembelajaran PKBM Putro Wali dengan Model Lesson Study di Ponpes Nurul Ulum Tagrineh Manoan Kecamatan Kokop Kabupaten Bangkalan. PERDIKAN (Journal of Community Engagement), $1(2)$. https://doi.org/10.19105/pjce.v1i2.2680

Permen dikbud Nomor 22 tahun 2016. (2016). Standar Proses Pendidikan Dasar dan Menengah.

Rahayu, S., Sutrio, Hikmawati, \& Verawati, N. N. S. P. (2018). Pelatihan Lesson Study Bagi Guru-Guru SMA Muhammadiyah Mataram Untuk Meningkatkan Profesionalisme Guru. Jurnal Pendidikan dan Pengabdian Masyarakat, 1(2), 300304.

Slamet Mulyana (2007). Lesson Study (Makalah).

Sudirman (2013). Peningkatan Kemampuan Mekaksanakan Pembelajaran Fisika Melalui Lesson Study dengan AEE dan Prapembelajaran di SMA Komadya Palembang Sumatera Selatan.
Sudrajat, A. (2008). Lesson study untuk meningkatkan proses dan Hasil Pembelajaran. http://akhmadsudrajat. wordpress. com.

Sugiyono (2013). Metode Penelitian Lesson Study Research Group. httc.edu/lessonstudy/ whatislessonstudy. Html.

Sukirman (2011). Work Shop Dan Sosialisasi Lesson Studi. Upaya Meningkatkan Mutu Perkuliahan Pada Perguruan Tinggi Melalui Lesson Studi.

Susanto, H. A. (2011). Sosialisasi Lesson Studi. Undang-undang No.14 tahun 2005. (2005). tentang guru dan dosen.

Undang-undang No.20 tahun 2003. (2003). Sistem Pendidikan Nasional. 